\title{
Influence of natural and anthropogenic sources on PM10 air concentrations in Spain
}

\author{
M. S. Callén, J. M. López \& A. M. Mastral \\ Energy and Environment Department, \\ Instituto de Carboquímica (ICB-CSIC), Spain
}

\begin{abstract}
Particulate matter samples less than or equal to $10 \mu \mathrm{m}$ (PM10) were collected by using a high-volume air sampler during cold and warm seasons at two different areas in Spain: a rural area which was considered a "non-polluted" area and an urban city, Zaragoza (Spain) in which vehicular traffic and small industries were the potential pollution sources. The PM10 samples were analyzed to determine their organic (polycyclic aromatic hydrocarbons (PAH) by gas chromatographymass spectrometry mass spectrometry) and inorganic (ions: anions and cations, by ionic chromatography and by inductively coupled plasma optical emission spectroscopy (ICP-OES)) composition.

Higher PAH and ions concentrations were obtained in the urban area during the cold season when compared to the warm season and these concentrations were always higher than the ones obtained in the rural area. Fuel combustion sources associated with coal, natural gas, vehicular traffic and biomass combustion were the major anthropogenic PM10 pollution sources obtained by principal component analysis (PCA) in the urban area although natural sources associated with marine aerosol were also contributing to this PM10. Cluster analysis corroborated these sources and allowed classifying samples as a function of the meteorological variables, $\mathrm{PAH}$ and ion concentrations.

Keywords: air pollution, PM10, PAH, anthropogenic sources, anions, cations, $P C A$, cluster analysis.
\end{abstract}

\section{Introduction}

Particulate matter is considered one of the main air pollutants, whose origin can be attributed to natural and to anthropogenic sources, at higher proportions. Due 
to its different nature, organic and inorganic pollutants can be found. Into the organic pollutants, PAH constitute a special group of pollutants which are formed by two or more fused aromatic rings only containing $\mathrm{C}$ and $\mathrm{H}$. The main concern of studying PAH is related to their mutagenic and/or carcinogenic character [1]. Other groups of pollutants which can be included in the PM are inorganic pollutants and ions of inorganic and/or organic nature. Nitrate and sulphate constitute two of the main secondary inorganic components of aerosol and they do not only affect climate change but also predominantly control the aerosol acidification and conductivity via acid rain precursors, mainly sulphur and nitrogen oxides. Therefore, only knowing and characterizing the pollution sources, especially those of anthropogenic character, will be possible to abate PM pollutions and to take further control.

This work is based on the characterization of the PM10, in particular PAH and ions in two different sampling sites: one mainly affected by anthropogenic sources (urban area) and another one considered as "non-polluted" area. A comparison of the pollutants in both sampling sites was carried out for both seasons: warm and cold seasons. The study of the main pollution sources was also carried out by using source apportionment techniques, such as principal component analysis and statistical tools based on cluster analysis in the most polluted area corresponding to the urban sampling site.

\section{Experimental}

\subsection{Sampling description}

The study was performed in the city of Zaragoza (ZGZ), located in the NorthEast of Spain $\left(41^{\circ} 39^{\prime} 49.38^{\prime \prime} \mathrm{N}\right.$; $\left.0^{\circ} 53^{\prime} 16.68^{\prime \prime} \mathrm{W}\right)$, by using a Graseby Andersen high-volume air sampler provided with a PM10 cut off inlet to collect particulate phase in a Teflon-coated, fibre-glass filter $(0.6 \mu \mathrm{m}$ pore size; $20.5 \mathrm{~cm} \times 25.5 \mathrm{~cm})$ [2]. Traffic pollution and industrial activities were the main potential pollution sources of this place. The second site was Torrelisa (Huesca) (PIR) $\left(42^{\circ} 27^{\prime} 36^{\prime \prime} \mathrm{N} ; 0^{\circ} 10^{\prime} 48^{\prime \prime} \mathrm{E}\right)$ localized in the Pyrenees Mountain and considered as representative of biogenic sources.

Samples were collected during two sampling periods: warm and cold seasons collecting a total of 30 samples for each sampling site during 2008 and 2009. More details regarding the sampling site were given in previous articles [2, 3].

\subsection{Ions analysis}

$1 / 8$ of the filter was extracted by ultrasonic bath for 30 minutes in $15 \mathrm{~mL}$ of Milli-Q water. The analyses of anions $\left(\mathrm{Cl}^{-}, \mathrm{NO}_{3}{ }^{-}, \mathrm{SO}_{4}{ }^{2-}, \mathrm{PO}_{4}{ }^{3-}\right)$ were carried out by ion chromatography (Metrohm) with conductivity detection and a Metrosep A Supp 5 anion column. The analyses of cations $\left(\mathrm{Na}^{+}, \mathrm{K}^{+}, \mathrm{Mg}^{2+}, \mathrm{Ca}^{2+}\right)$ were carried out by ICP-OES (JY 2000 Ultrace Horiba). More details regarding the analytical protocol are shown in a previous article [4]. 
The sulphate concentration of marine origin, $\mathrm{mSO}_{4}{ }^{2-}$ was determined indirectly by considering the $\mathrm{Na}^{+}$soluble concentration according to the ratio: $\mathrm{mSO}_{4}{ }^{2-} / \mathrm{Na}^{+}=0.25$ in weight [5]. The non-sea-salt-sulphate, $\mathrm{nmSO}_{4}{ }^{2-}$, generally of anthropogenic origin, was obtained by subtracting this value to the $\mathrm{SO}_{4}{ }^{2-}$ concentration.

The identification of compounds was based on the retention time and the quantification was made using calibration curve acquired with the external standards.

\subsection{PAH analysis}

The following PAH (phenanthrene (Phe), anthracene (An), 2+2/4methylphenanthrene $(2+2 / 4 \mathrm{MePhe}), \quad 9-$ methylphenanthrene (9MePhe), 1methylphenanthrene (1MePhe), 2,5-/2,7-/4,5-dimethylphenanthrene (Dimephe), fluoranthene (Fth), pyrene (Py), benz[a]anthracene (BaA), chrysene (Chry), benzo[b]fluoranthene $(\mathrm{BbF})$, benzo[k]fluoranthene $(\mathrm{BkF})$, benzo[e]pyrene $(\mathrm{BeP})$, benzo[a]pyrene (BaP), indeno[1,2,3-cd]pyrene (IcdP), dibenz[a,h]anthracene (DahA), benzo[ghi]perylene (BghiP) and coronene (Cor) were quantified according to previous publication using gas chromatography mass spectrometry mass spectrometry (GC-MS-MS) [2] with the internal standard method after Soxhlet extraction with dicloromethane.

\subsection{Meteorological variables}

The meteorological data in ZGZ and PIR were provided daily by the Estación Experimental de AULA-DEI (CSIC) and by DGA, respectively.

\subsection{Statistical tools}

The SPSS Version 15.0 statistical package was used as statistical tool: a) to evaluate the correlation between variables by using Pearson correlation coefficients, $b$ ) to test for significant differences in seasonal air concentrations by using a parametric test (Student's t-test of independent samples for each sampling place), c) to run principal component analysis (PCA) in order to find the main pollution sources and multiple linear regression and d) to apply cluster analysis for evaluation of data pattern and classification of data.

\section{Results and discussion}

\subsection{PM10 and PAH concentrations}

A brief summary of results obtained for each sampling site regarding PM10 and PAH concentrations $[2,6]$ during the warm and cold seasons for both sampling sites are shown in Table 1.

Higher PM10 and PAH concentrations were found during the cold season for both sampling sites with higher concentrations in ZGZ than in PIR. This finding is consistent with the localization of the sampling sites: the rural place was in the 
Table 1: Average concentration and standard deviation of ions $\left(\mathrm{ng} / \mathrm{m}^{3}\right)$, PM10 $\left(\mu \mathrm{g} / \mathrm{m}^{3}\right)$ and total PAH $\left(\mathrm{ng} / \mathrm{m}^{3}\right)$ for the whole period, for the warm and for the cold periods in PIR and in ZGZ.

\begin{tabular}{|c|c|c|c|c|}
\hline & & Whole period & Warm & Cold \\
\hline $\mathrm{Cl}^{-}$ & PIR & $20.97(54.80)$ & $1.06(2.50)$ & $40.87(73.42)$ \\
\hline & ZGZ & $655.00(693.20)$ & $123.26(110.43)$ & $1186.73(614.25)$ \\
\hline $\mathrm{NO}_{3}{ }^{-}$ & PIR & $1364.27(1614.63)$ & $122.65(78.76)$ & $2605.90(1443.92)$ \\
\hline & ZGZ & $3026.62(3904.35)$ & $1525.31(988.70)$ & $4527.92(5076.35)$ \\
\hline $\mathrm{nmSO}_{4}{ }^{2-}$ & PIR & $545.46(384.89)$ & $568.69(503.50)$ & $522.23(232.27)$ \\
\hline & ZGZ & $1790.22(1913.07)$ & $1680.18(675.23)$ & $1900.26(2664.43)$ \\
\hline $\mathrm{SO}_{4}{ }^{2-}$ & PIR & $594.44(397.82)$ & $598.46(516.01)$ & $590.42(251.82)$ \\
\hline & ZGZ & $1959.94(1926.57)$ & $1754.77(678.67)$ & $2165.11(2671.64)$ \\
\hline $\mathrm{Ca}^{2+}$ & PIR & $217.82(133.87)$ & $175.18(144.89)$ & $260.46(111.37)$ \\
\hline & ZGZ & $830.59(342.16)$ & $882.80(234.54)$ & $778.39(426.21)$ \\
\hline $\mathrm{K}^{+}$ & PIR & $142.03(80.26)$ & $88.87(45.16)$ & $195.18(72.53)$ \\
\hline & ZGZ & $241.34(324.70)$ & $103.88(43.74)$ & $378.79(419.51)$ \\
\hline $\mathrm{Na}^{+}$ & PIR & $199.78(143.53)$ & $126.79(54.88)$ & $272.78(168.42)$ \\
\hline & ZGZ & $678.88(584.63)$ & $298.38(108.86)$ & $1059.39(621.20)$ \\
\hline $\mathrm{PM} 10$ & PIR & $14(8.0)$ & $10(7.4)$ & $19(6.2)$ \\
\hline & ZGZ & $26(16)$ & $21(5.5)$ & $30(21)$ \\
\hline Total PAH & PIR & $0.266(0.235)$ & $0.097(0.117)$ & $0.455(0.176)$ \\
\hline & ZGZ & $5.30(5.98)$ & $2.20(1.45)$ & $8.40(7.18)$ \\
\hline
\end{tabular}

mountain with plenty of vegetation and minimum anthropogenic sources whereas the urban area was characterized by high traffic, population and predominance of anthropogenic sources. Meteorological factors related to low solar radiation, low temperature and low photochemical decomposition in addition to contribution of domestic heating during the cold season could explain these higher pollutant concentrations. Regarding the PAH concentrations in PIR, most of the individual PAH concentrations were below the detection limit indicating a lower impact of anthropogenic sources, especially during the warm season.

\subsection{Ions analysis}

Regarding the concentrations of ions in both sampling sites, it is remarkable to say that nitrate ion was found to be the largest component present in the samples at both sampling sites with the following decreasing order $\mathrm{NO}_{3}{ }^{-}>\mathrm{nmSO}_{4}{ }^{2-}$ $>\mathrm{Ca}^{2+}>\mathrm{Na}^{+}>\mathrm{K}^{+}$(Table 1). This trend was only modified during the warm season in the rural area, being $\mathrm{nmSO}_{4}{ }^{2-}$ the majority ion corroborating the enhanced $\mathrm{SO}_{4}{ }^{2-}$ concentration due to the increased photochemical activity reported by different authors [7, 8] during the warm season. On the contrary, the winter period with low temperature and high relative humidity favoured the formation of $\mathrm{NO}_{3}^{-}[9,10]$. For each ion, the concentration was always higher in $\mathrm{ZGZ}$ than 
in PIR and it was favoured by the higher impact of anthropogenic activities carried out in ZGZ city.

The main sources of $\mathrm{NO}_{3}{ }^{-}$are due to the use of fertilizers in agricultural zones close to the sampling point that could be resuspended and the oxidation of $\mathrm{NO}_{\mathrm{x}}$. This last one is the most significant precursor of nitrate, proceeding of coal combustion, biomass burning, industry and traffic emissions, all of them local sources that play a major role near the monitoring site in $\mathrm{ZGZ} \mathrm{NO}_{3}{ }^{-}$represented the $10 \%$ in weight of the PM10 and it showed a positive and significant correlation at $99 \%$ level with $\mathrm{nmSO}_{4}{ }^{2-}$, total $\mathrm{PAH}, \mathrm{PM} 10, \mathrm{Ca}^{2+}$ and $\mathrm{K}^{+}$indicating that they came from a similar type of emission source, which could be associated with fossil fuel combustion including vehicular emissions. The main possible forms of nitrates could be $\mathrm{Ca}\left(\mathrm{NO}_{3}\right)_{2}$ and $\mathrm{KNO}_{3}$.

In addition to its marine origin, sulphate in ambient air mainly comes from photochemical oxidation of sulphur containing precursors such as $\mathrm{SO}_{2}, \mathrm{H}_{2} \mathrm{~S}, \mathrm{CS}_{2}$ where sulphur dioxide is the largest contributor [11]. The precursor of sulphate aerosol may be released from industrial source, coal combustion as well as diesel combustion and oil-fired power plant profiles, which contain higher sulphate concentrations than most of the coal-fired power plant, all of them local pollution sources affecting ZGZ. Other main source is due to mineral aerosols. In ZGZ, $\mathrm{nmSO}_{4}{ }^{2-}$ represented a $6.6 \%$ in weight of the PM10 and it was correlated at $99 \%$ level with $\mathrm{NO}_{3}{ }^{-}$and $\mathrm{K}^{+}$indicating that the main form of non marine sulphate was $\mathrm{K}_{2} \mathrm{SO}_{4}$. The average percentage of $\mathrm{nmSO}_{4}{ }^{2-}$ versus $\mathrm{SO}_{4}{ }^{2-}$ was $84.3 \%$ indicating that its main source had anthropogenic origin.

$\mathrm{Cl}^{-}$represented a 3\% in weight of the PM10 and it was correlated at $99 \%$ level with $\mathrm{Na}^{+}$showing that sea salt was the most important source of this ion in ZGZ. Regarding cations, it is remarkable to say that $\mathrm{Mg}^{2+}$ was not detected in any sample. $\mathrm{K}^{+}$represented $0.9 \%$ in weight of the PM10 in ZGZ and its main sources, in addition to the marine aerosol and soil resuspension, are anthropogenic sources: forest fires, agricultural or biomass burning [12]. It has been used as a biomass burning tracer in source apportionment $[13,14]$ and it could also indicate the contribution of waste incineration plants and paper fabrics located in the surroundings of the city. Its positive and significant correlation with PM10, total PAH, $\mathrm{NO}_{3}{ }^{-}$and $\mathrm{nmSO}_{4}{ }^{2-}$ indicated its possible main anthropogenic origin.

$\mathrm{Ca}^{2+}$ (3.7\% in weight of the PM10) whose origin is mainly mineral due to soil resuspension $[15,16]$ and activities related to construction, is the majority cation in both sampling sites except in the cold season where $\mathrm{Na}^{+}(3.5 \%$ in weight of the PM10) is the predominant.

Regarding the seasonal behaviour of ions, it was observed that in $\mathrm{ZGZ} \mathrm{Cl}^{-}$and $\mathrm{Na}^{+}$were statistically different at $99 \%$ level whereas $\mathrm{NO}_{3}^{-}$and $\mathrm{K}^{+}$were statistically different at $95 \%$ level indicating that sources producing these pollutants followed a different trend in both seasons.

In PIR the concentrations of all ions were higher during the cold season with the exception of $\mathrm{nmSO}_{4}{ }^{2-}$ that was slightly higher during the warm season. $\mathrm{NO}_{3}{ }^{-}$ $\left(6.8 \%\right.$ in weight of the PM10), $\mathrm{K}^{+}\left(0.97 \%\right.$ in weight of the PM10) and $\mathrm{Na}^{+}$ $(1.4 \%)$ were statistically different during the warm and cold seasons. As 
happened in $\mathrm{ZGZ}, \mathrm{NO}_{3}{ }^{-}$was statistically correlated at $99 \%$ level with total $\mathrm{PAH}$, PM10, $\mathrm{Ca}^{2+}\left(1.4 \%\right.$ in weight of the PM10), $\mathrm{K}^{+}$and also with $\mathrm{Na}^{+}$so that the main forms of nitrates were $\mathrm{Ca}\left(\mathrm{NO}_{3}\right)_{2}, \mathrm{KNO}_{3}$ and $\mathrm{NaNO}_{3}$. The main difference with regard to $\mathrm{ZGZ}$ was related to $\mathrm{NO}_{3}{ }^{-}$and $\mathrm{nmSO}_{4}{ }^{2-}$ (4.0\% in weight of the PM10), which were not correlated indicating that they originated from different secondary sources. The non-marine sulphate $(4.0 \%$ in weight of the PM10) was mainly correlated to $\mathrm{Ca}^{2+}$ as $\mathrm{CaSO}_{4}$ and it could have a natural origin.

The mass ratios of $\mathrm{SO}_{4}{ }^{2-} / \mathrm{NO}_{3}{ }^{-}$were also used to distinguish the predominance of stationary and/or mobile sources of sulphur and nitrogen in the atmosphere $[17,18]$. Whereas in ZGZ this mean ratio was 1.11 , indicative of mobile sources, in PIR this ratio was 2.47 indicating that stationary sources were predominant. This seems to be reasonable by considering the affluence of traffic in ZGZ compared to PIR (background rural area). This difference was more remarkable when the ratios were calculated for the two different seasons. In this case, the ratio for PIR during the warm season was 4.16 whereas it was 0.40 in the cold season. In ZGZ these ratios were 1.4 and 0.8 for the warm and cold seasons, respectively. Therefore the influence of stationary sources was reflected in PIR during the warm season and it could be attributed to forest fires and agriculture fires produced at the dry South Mediterranean countries during those dates.

\subsection{Principal component analysis}

Because ZGZ was the sampling point with the highest impact of pollution sources, PCA was applied to samples taken in ZGZ for both sampling periods in order to discern the main pollution sources. Data were auto-scaled before PCA by subtracting the mean concentration of each variable from the observed concentration followed by division of the standard deviation of the concentration of each variable. All factors with eigenvalues over 1 were extracted according to Kaiser-Meyer-Olkin KMO and Bartlett's test of sphericity and were rotated using the Varimax method. A total of 19 variables were taken and three factors were obtained explaining $88 \%$ of the variance. The communalities were also higher than 0.6 for all variables and those variables with low coefficients $(<0.6)$ were not used in interpreting the principal components.

Figure 1 shows the loading plot for individual components of PAH and ions in ZGZ and the possible pollution sources. The first factor explained $71.3 \%$ of the variance and was associated to most of the PAH: Phe, An, 2+2/4MePhe, Fth, Py, BaA, Chry, IcdP+DahA, BghiP and Cor. Ph, Fth, Py, BaA and Chy are markers of coal combustion [19] with predominance of Ph, Fth and Py [20]. In $\mathrm{ZGZ}$, coal is the most important energy source and is used widely for industrial purposes, especially in the power industry and as fuel in the electric power supply from coal-burning power plants. It is remarkable the presence of three thermal power stations in Aragón. Moreover natural gas is also used as main domestic heating, which is reflected by a high fraction of BaA and Chry [21]. In addition, BghiP [22] and IcdP [23] are tracers of vehicular emissions. Therefore, this factor was related to fossil fuel combustion and vehicular emissions. 


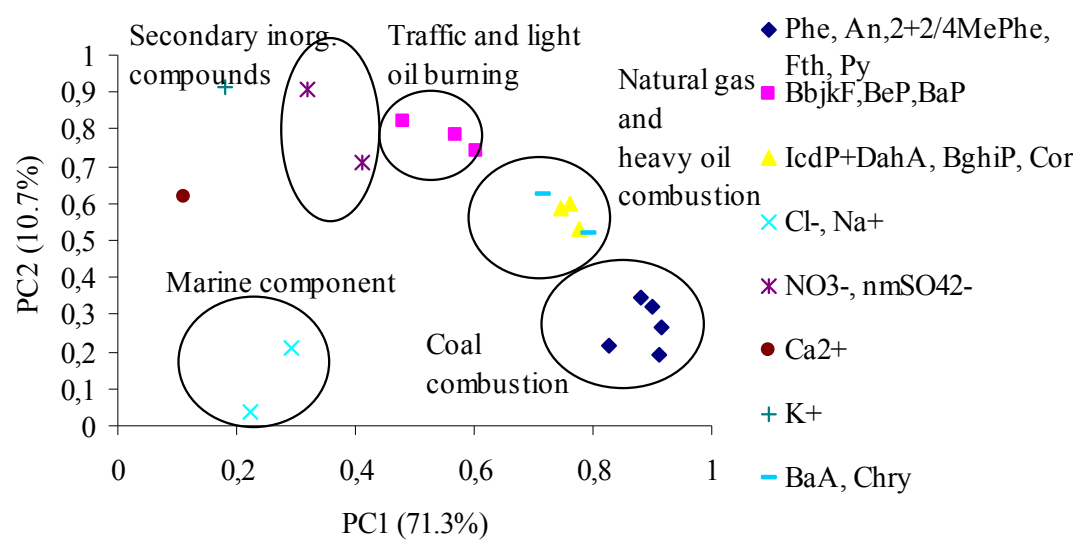

Figure 1: Principal component analyses loading plot for individual components of PAH and ions in ZGZ.

The second factor explained $10.7 \%$ of the variance and was related to $\mathrm{BbjkF}$, $\mathrm{BeP}, \mathrm{BaP}, \mathrm{NO}_{3}^{-}, \mathrm{nmSO}_{4}^{2-}$ and $\mathrm{K}^{+}$. $\mathrm{BeP}$ and $\mathrm{BaP}$ are the fingerprints of light oil burning [24] and $\mathrm{K}^{+}$is a marker of biomass combustion [13, 14]. Nevertheless, $\mathrm{BbF}, \mathrm{BeP}$ and $\mathrm{BaP}$ are also found in the ambient air at the traffic source [25]. Therefore this factor could be associated with industrial emissions including oil and wood burning as well as traffic source. Finally, the last factor associated with $\mathrm{Cl}^{-}$and $\mathrm{Na}^{+}$explained $6.2 \%$ of the variance and was related to marine component. Figure 1 shows the loading plot for individual components of PAH and ions in ZGZ and the possible pollution sources.

Afterwards, the absolute principal component scores APCS were used based on the PCA factor scores to derive quantitative estimates of source contributions and source profiles [26]. A $16 \%, 47 \%$ and $4 \%$ of the PM10 was explained according to the factors mentioned previously. A $32 \%$ of the experimental particulate matter was not explained and the correlation between the experimental and the modelled particulate matter was 0.87 with a slope of 0.99 showing a good correlation between the experimental and the modelled PM10. Figure 2 shows the temporal evolution of each factor along the sampling dates. It is observed that the maximum in PM10 concentrations were obtained during the cold season and corresponded to maximum in the industry+traffic factor.

Results were also evaluated by cluster analysis obtaining two different dendograms by using variables (Figure 3 ) and by using dates (Figure 4).

The dendogram created when clustering the variables using Ward's method (squared Euclidean distance, variables normalized using z-scores) confirmed the presence of three main groups with different sub-divisions. In this way, in the first cluster, two different sub-groups can be considered: on the one hand, Fth, Py, An, 2+2/4Mephe, Phe, PAH of low molecular weight and 3-4 rings which would be attributed to fossil fuel combustion. On the other hand, BaA, Chry, IcdP+DahA, BghiP and Cor which would be mainly associated with natural gas and traffic emissions. A second cluster would be constituted by $\mathrm{Cl}^{-}$and $\mathrm{Na}^{+}$ 


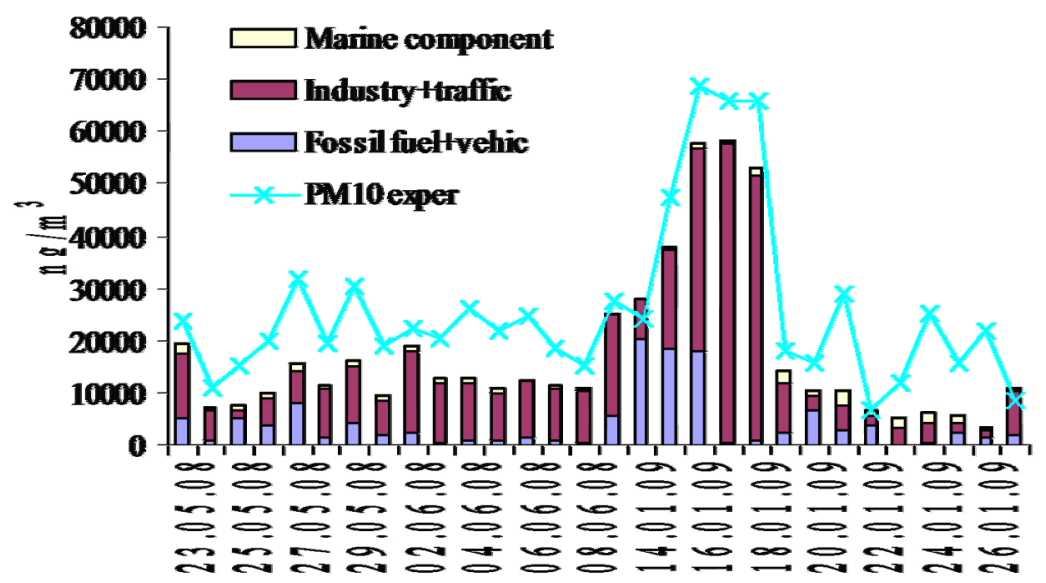

Figure 2: Contribution of each factor obtained by PCA/APCS $\left(\mathrm{ng} / \mathrm{m}^{3}\right)$ and PM10 concentration $\left(\mathrm{ng} / \mathrm{m}^{3}\right)$ for each sampling date in ZGZ.

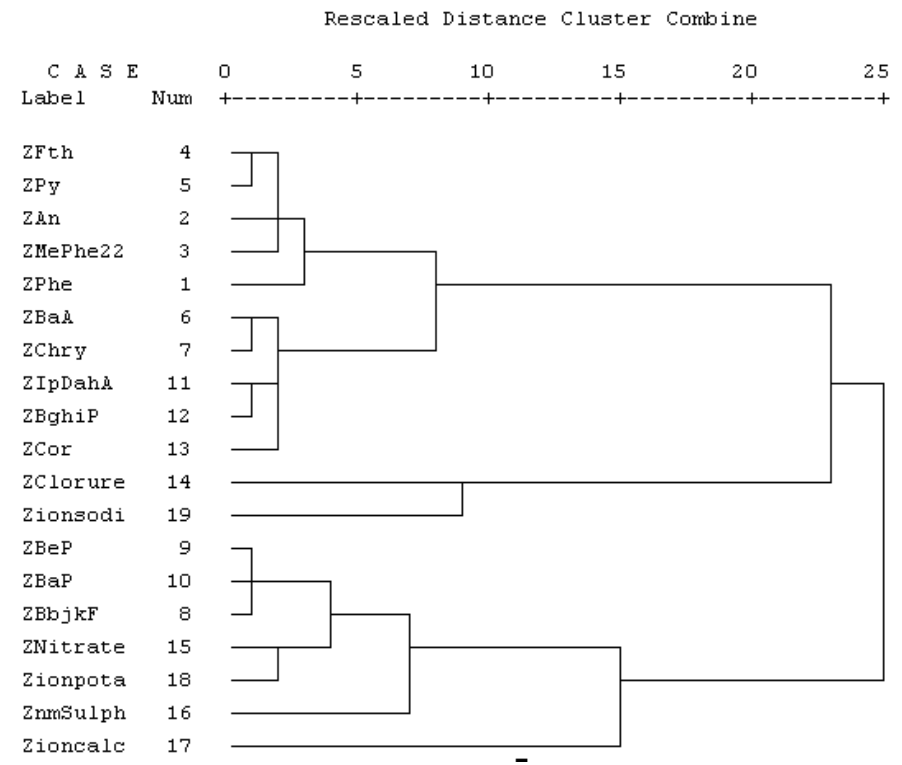

Figure 3: $\quad$ Cluster dendogram based on $\mathrm{PAH}$ and ions using Ward's method and Euclidean distance in ZGZ (variables normalized using Zscores).

associated with marine component. The third major group would be constituted of, $\mathrm{BeP}, \mathrm{BaP}, \mathrm{BbjkF}, \mathrm{NO}_{3}^{-}, \mathrm{K}^{+}, \mathrm{nmSO}_{4}{ }^{2-}$ and $\mathrm{Ca}^{2+}$ including industrial and vehicular emissions corroborating the different pollution sources obtained previously by PCA. 
Dendrogram using Jard Hethod

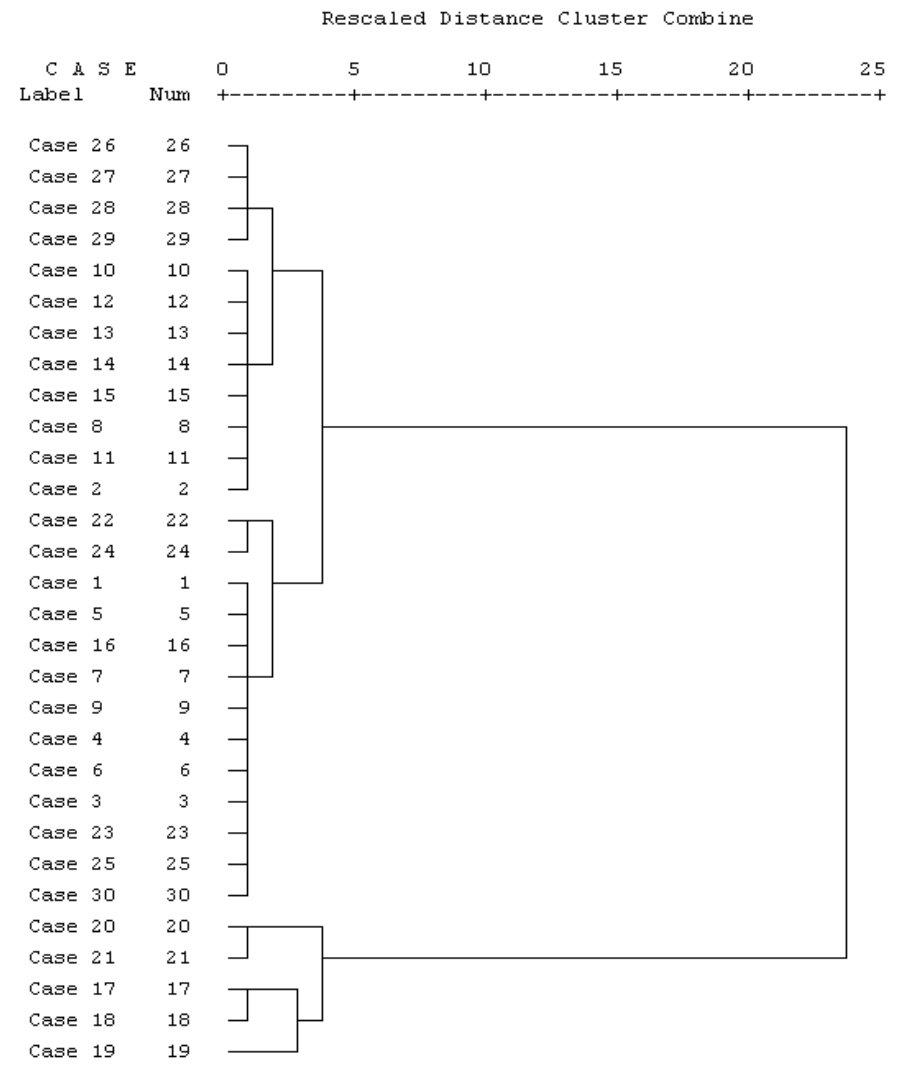

Figure 4: Cluster dendrogram based on dates using Ward's method and Euclidean distance in ZGZ (Samples taken during consecutive days; Num 1=23/05/2008; Num 15=08/06/2008; Num $16=13 / 01 / 2009$; Num $30=27 / 01 / 2009$ ).

A new dendogram was obtained when the same method was also used to group the different cases as a function of the sampling dates (Figure 4). Two main clusters were distinguished. A first cluster grouping most of the samples: 2 , $8,10-15,26-29,22,24$ and $1,5,16,23,25,30,7,9,4,6,3$ and a second cluster corresponding to samples 17-21 (14-18 January 2009), which were associated to the highest PAH concentrations obtained during the cold season. Trying to get the variables, which were statistically different among these clusters, an independent $\mathrm{t}$-test was performed and temperature, solar radiation, relative humidity, total $\mathrm{PAH}, \mathrm{Cl}^{-}, \mathrm{NO}_{3}{ }^{-}$and $\mathrm{K}^{+}$were the variables statistically different at $95 \%$ level. In this way, typical conditions of winter season: low temperature, low solar radiation and high relative humidity favoured the accumulation of the 
following pollutants: $\mathrm{PM} 10$, total $\mathrm{PAH}, \mathrm{Cl}^{-}, \mathrm{NO}_{3}{ }^{-}$and $\mathrm{K}^{+}$. Inside the first cluster, two subgroups could be distinguished. Samples 2, 8, 10-15 were taken during the warm period and samples 26-29 were collected during the cold period. The variables statistically different between both groups were the ions concentration, the temperature and the solar radiation where the lower temperature and the solar radiation registered for samples 26-29 favoured the high pollutants concentration. The second subgroup inside the first cluster corresponded to samples 1, 5, 16, 23, 25, 30, 7, 9, 4, 6, 3 (first subgroup), 22 and 24 (second subgroup). No variables statistically different between the two subgroups were found although samples 22 and 24, which were collected during the cold period presented meteorological conditions typical of winter season with lower average temperature than the other subgroup.

The second main cluster corresponded to samples 17-21 (14-18 January 2009), which were associated to the highest PAH concentrations during the cold season. Inside this group, two different sub-groups could be distinguished. Samples 17-19 and 20-21. By applying a t-test to independent samples, no statistical differences were found among variables, the only difference was that samples 17-19 were taken during weekdays whereas samples 20-21 were taken during the weekend in which San Juan bonfires festivals were celebrated.

\section{Acknowledgements}

Authors would like to thank Aula Dei-CSIC (R. Gracia) for providing the meteorological data, to the Gobierno de Aragón (DGA) for partial financial support, to the Ministry of Science and Innovation (Spain) through the project CGL2009-14113-C02-01 for funding as well as the Fondo Europeo de Desarrollo Regional (FEDER). J.M. López would also like to thank CSICSpanish Government for his Ramón and Cajal contract.

\section{References}

[1] Luch, A., (ed). The Carcinogenic Effects of Polycyclic Aromatic Hydrocarbons. Imperial College Press, ISBN 1-86094-417-5, London, 2005.

[2] Callén, M.S., López, J.M. \& Mastral, A.M., Characterization of PM10bound polycyclic aromatic hydrocarbons in the ambient air of Spanish urban and rural areas. Journal of Environmental Monitoring, 13, pp. 319327, 2011.

[3] Callén, M.S., de la Cruz, M. T., López, J.M., Murillo, R., Navarro, M.V. \& Mastral, A. M., Long-range atmospheric transport and local pollution sources on PAH concentrations in a South European urban area, Fulfilling of the European Directive. Water, Air and Soil Pollution, 190, pp.1-4, 2008.

[4] Callén, M.S., de la Cruz, M.T., López, J.M., Murillo, R., Navarro, M.V. \& Mastral, A.M., Comparison of receptor models for source apportionment of the PM10 in Zaragoza (Spain). Chemosphere, 76, pp. 1120-1129, 2009. 
[5] Duce, R.A., Arimoto, R., Ray, B.J., Unni, C.K. \& Harder, P.J., Atmospheric trace elements at Enewetak Atoll: 1, Concentrations, sources and temporal variability. Journal of Geophysical Research, 88, pp. 53215342, 1983.

[6] Callén, M.S., López, J.M. \& Mastral, A.M., Seasonal variation of Benzo(a)pyrene in the Spanish airborne PM10. Multivariate linear regression model applied to estimate $\mathrm{BaP}$ concentrations. Journal of Hazardous Materials, 180, pp. 648-655, 2010.

[7] Khan, Md. F., Hirano, K. \& Masunaga, S., Quantifying the sources of hazardous elements of suspended particulate matter aerosol collected in Yokohama, Japan. Atmospheric Environment, 44, pp. 2646-2657, 2010

[8] Husain, L. \& Dutkiewicz, V.A., A long-term (1972-1988) study of atmospheric $\mathrm{SO}_{4}$ : regional contributions and concentration trends. Atmospheric Environment, 24(A), pp. 1175-1187, 1990.

[9] Park, S.S. \& Kim, Y.J., Source contributions to fine particulate matter in an urban atmosphere. Chemosphere, 59, pp. 217-226, 2005.

[10] Mariani, R.L. \& de Mello, W.Z., PM2.-10, PM2.5 and associated watersoluble inorganic species at a coastal urban site in the metropolitan region of Río de Janeiro. Atmospheric Environment, 41, pp. 2887-2892, 2007.

[11] Khoder, M.I., Atmospheric conversion of sulphur dioxide to particulate sulphate and nitrogen nitric acid in an urban area. Chemosphere, 49, pp. 675-684, 2002.

[12] John, K., Karnae, Crist, K., Kim, M. \& Kulkarni, A., Analysis of trace elements and ions in ambient fine particulate matter at three elemental schools in Ohio, Journal of Air Waste Management Association, 57, 394406, 2007.

[13] Marmur, A., Mulholland, J.A. \& Russell, A.G., Optimized variable source profile approach for source apportionment. Atmospheric Environment, 41, pp. 493-505, 2007.

[14] Sheffield, A.E., Gordon, G.E., Currie, L.A. \& Riederer, G.E., Organic elemental and isotopic tracers of air pollution sources in Albuquerque, NM. Atmospheric Environment, 28, pp. 1371-1384, 1994

[15] Zhuang, H., Chan, C.K., Fang, M. \& Wexler, A.S., Size distribution of particulate sulfate, nitrate and ammonium at a coast site in Hong Kong. Atmospheric Environment, 33, pp. 848-853, 1999.

[16] Hedge, P., Pant, P., Naja, M., Dumka, U.C. \& Sagar, R., South-Asian dust episode in June 2006: aerosol observations in the central Himalayas. Geophysical Research Letters, 34, L23802, 2007.

[17] .Yao, X., Fang, M. \& Chan, C.K., The water-soluble ionic composition of PM2,5 in Shanghai and Beijing, China. Atmospheric Environment, 36(26), pp. 4223-4234, 2002.

[18] Xiu, G., Zhang, D., Chen, J., Huang, X., Chen, Z., Guo, H. \& Pan, J., Characterization of major water-soluble inorganic ions in size-fractionated particulate matters in Shanghai campus ambient air. Atmospheric Environment, 38, pp. 227-236, 2004. 
[19] Duval, M.M. \& Friedlander, S.K. Source resolution of polycyclic aromatic hydrocarbons in the Los Angeles atmosphere, EPA-600/2-81-161, PB82121336, U.S. EPA, Washington, DC, 1981.

[20] Zuo, Q., Duan, Y.H., Yang, Y., Wang, X.J. \& Tao, S., Source apportionment of polycyclic aromatic hydrocarbons in surface soil in Tianjin, China. Environmental Pollution, 147, pp. 303-310, 2007.

[21] Simcik, M.F., Eisenreich, S.J. \& Lioy, P.J., Source apportionment and source/sink relationships of PAHs in the coastal atmosphere of Chicago and Lake Michigan. Atmospheric Environment, 33, pp. 5071-5079, 1999.

[22] Boonyatumanond, R., Wattayakom, G., Amano, A., Inouchi, Y. \& Takada, H., Reconstruction of pollution history of organic contaminants in the upper Gulf of Thailand by using sediment cores: First report from Tropical Asia Core (TACO) project. Marine Pollution Bulletin, 54, pp. 554-565, 2007.

[23] Larsen, R.K. \& Baker, J.E., Source apportionment of polycyclic aromatic hydrocarbons in the urban atmosphere: a comparison of three methods. Environmental Science and Technology, 37, pp. 1873-1881, 2003.

[24] Bari, M.A., Baumbach, G., Kuch, B. \& Scheffknecht, G., Wood smoke as a source of particle-phase organic compounds. Atmospheric Environment, 43, pp. 4722-4732, 2009.

[25] Lee, W-J., Wang, Y-F., Lin, T-C., Chen, Y-Y., Lin, W-C., Ku, C-C. \& Cheng, J-T., PAH characteristics in the ambient air of traffic source. The Science of the Total Environment, 159, pp. 185-200, 1995.

[26] Thurston, G.D. \& Spengler, J.D., A quantitative assessment of source contributions to inhalable particulate matter pollution in metropolitan Boston. Atmospheric Environment, 19, pp. 9-25, 1985. 